\title{
A Holistic Approach to Improving the Musculoskeletal Health of City Bus and Long-Distance Bus Drivers
}

\author{
Paula Kärmeniemi ${ }^{1}$, Nina Nevala ${ }^{1,2}$ Arto Reiman $^{1}$, Irmeli Pehkonen ${ }^{*}, 1$ \\ ${ }^{1}$ Finnish Institute of Occupational Health, Topeliuksenkatu 41 a A, FI-00250 Helsinki, Finland \\ ${ }^{2}$ University of Jyväskylä, Gerontology Research Centre and Department of Health Sciences, Box 35, FI-40014 \\ University of Jyväskylä, Finland
}

\begin{abstract}
Purpose: To compare the work-related and lifestyle factors that support the musculoskeletal health of city bus (CB) drivers and long-distance bus (LDB) drivers, and to find solutions for improving drivers' health.

Methods: The participants were 62 bus drivers (aged 34-64 years). Data were gathered using a questionnaire, interviews and a workshop. Altogether $27 \mathrm{CB}$ and $35 \mathrm{LDB}$ drivers responded to the questionnaire, and four drivers were interviewed.

Results: The prevalence of musculoskeletal disorders (MSDs) was higher among the CB drivers than among the LDB drivers. The difference was statistically significant $(\mathrm{p}<0.05)$ for shoulder pain. The CB drivers more often reported awkward neck postures than the LDB drivers, whereas the LDB drivers performed manual lifting tasks more frequently. The CB drivers were more often exposed to psychosocial load factors and unhealthy lifestyle factors than the LDB drivers. The LDB drivers rated the usability of bus cabs as better than the ratings of the CB drivers.

Conclusion: The needs of both LDB and CB drivers must be considered when ergonomic interventions and a holistic approach are applied in bus trade companies. There is a need for ergonomic bus cabs; good maintenance of buses and work equipment; development of work organization; and training on work ergonomics, lifestyle, and work content issues.
\end{abstract}

Keywords: Bus drivers, ergonomics, holistic approach, lifestyle, musculoskeletal health, usability.

\section{INTRODUCTION}

A holistic approach that broadly takes into account the work environment (e.g. physical and psychosocial work environmental factors), competence, and individual factors (e.g. health issues, lifestyle) is needed to enhance the musculoskeletal health of bus drivers [1-3]. Action research methodology and participatory methods are effective ways in which to achieve this [1], and have similar key characteristics to macroergonomic approaches [4].

In addition to musculoskeletal disorders (MSDs), bus drivers also have other health problems [5-7], which are known to be associated with risk factors typical for bus drivers [1,2]. This is why the knowledge of bus drivers' work content is essential when trying to affect their health. The work tasks of a bus driver can be divided into 1) preparation tasks, 2) physical vehicle control tasks (e.g. tasks related to driving), 3) cognitive vehicle control tasks, 4) route/timetable tasks, 5) passenger-related tasks, 6) communication tasks, and 7) personal control tasks (e.g. making adjustments to the seat, sun visor, and ensuring that they drink enough fluids) [8]. The amounts of each task differ depending on the area (e.g. big city versus rural areas) and routes that the drivers operate. For example, CB drivers' work includes more stops with rapid deceleration and

*Address correspondence to this author at the Finnish Institute of Occupational Health, Topeliuksenkatu 41 a A, FI-00250 Helsinki, Finland; Tel: +358 40 7083784; E-mail: irmeli.pehkonen@ttl.fi acceleration of the vehicle, as well as driving on cobble stones [9]. On the other hand, LDB drivers' work contains manual material handling, especially in Finland, where bus companies carry freight on their buses (Fig. 1) [10].

Prolonged periods of inactivity while driving and sitting cause bus drivers physical strain and can lead to musculoskeletal disorders [7, 11], which are hazardous to health in general [12-16].

A poor visual and acoustic environment, thermal conditions, and the usability of the seat and cab structures $[7$, $11,17,18]$ may be risks to drivers' wellbeing at work.

Psychosocial work environment factors also associate with the occurrence of MSDs [19] and with bus drivers' psychosocial strain [7, 17, 20]. These are, for example, factors linked to working time and time pressure at work (e.g. tight route schedules) $[7,17,20]$, interaction with passengers and other road users $[6,17]$, management issues, ticketing, and cab ergonomics [17, 18].

Bus drivers' levels of competence should be taken into account in measures aimed at improving drivers' health [3]. The "bus driver task analysis" by Salmon et al. [8] showed that bus drivers' work tasks require various skills, which need to be put into action in complex environments. Brunoro et al. [21] stated that "driver activity is permeated with random events" and "in the management of these circumstances competence becomes apparent". Bus drivers' lack of competence can result in psychological and physical stress [7]. 


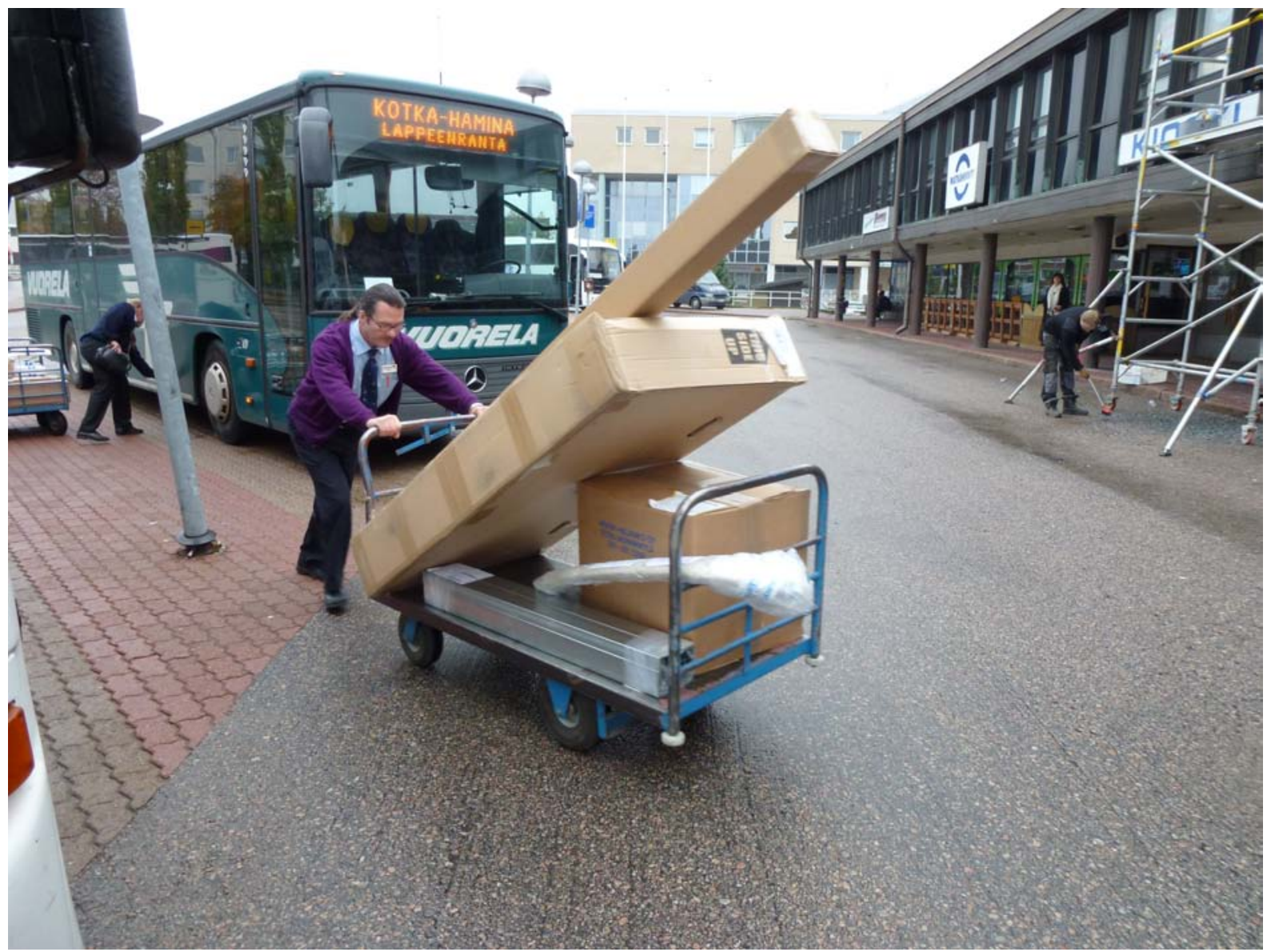

Fig. (1). Work of long-distance bus (LDB) drivers includes handling cargo at bus terminals.

Professional drivers' lifestyles also need attention. An unhealthy lifestyle is a well-known risk factor for professional drivers [7, 20,22], who often tend to have an inactive lifestyle due to lack of time and place to exercise [23], and poor diet. This originates from both the driver culture and lack of opportunities for healthy eating [7, 24]. Poor diet and inactivity often lead to overweight and obesity $[25,26]$. Long, irregular working hours are associated with short sleep, which in turn is associated with health risks such as obesity [27, 28].

No studies were found on the differences between the musculoskeletal health, lifestyle and ergonomic load factors of $\mathrm{CB}$ and LDB drivers. The aim of this study was to compare the work-related and lifestyle factors that support the musculoskeletal health of CB drivers and LDB drivers and to find solutions for improving drivers' health. The theoretical framework was modified from Poulsen et al. [3] "Four-leaf-clover" model (Fig. 2).

\section{MATERIALS AND METHODOLOGY}

\section{Study Design}

This was a cross-sectional study conducted in 2010-2011. The data were gathered from one large bus service company operating in two small towns in Finland. In this company, CB drivers operated inside city areas and the LDB drivers operated between towns. The data were gathered through a questionnaire, interviews and a workshop.

\section{Participants}

The questionnaire was administered to all the workers $(n=115)$ in one section of the company. Altogether 66 bus drivers $(57 \%)$ responded. However, four drivers did not respond to the question related to $\mathrm{CB}$ or LDB driving, and, therefore, their responses were not available for the subanalyses. Hence the final number of respondents was 62 bus drivers (aged 34-64 years) who worked as $\mathrm{CB}(\mathrm{n}=27)$ or LDB $(n=35)$ drivers. The median of work experience was 18 years for CB drivers and 14 years for LDB drivers. (Table $\mathbf{1}$ ).

Two thirds of the respondents were men. The CB drivers group had somewhat more women, respondents were slightly older, and the proportion of overweight and obese workers was greater than that among LDB drivers (Table 1).

\section{Questionnaire}

A questionnaire (paper form) was used to assess MSDs, work ability, workload factors, accidents and safety at work, the usability of bus cabs, and lifestyle factors.

Musculoskeletal pain was elicited with one dichotomous question (yes/no) regarding the following anatomical areas: neck, shoulders, low back, hips, knees, and ankles. Questions were modified from the validated Nordic Musculoskeletal Questionnaire [29]. In addition, the amount and content of guidance on the prevention of musculoskeletal health 


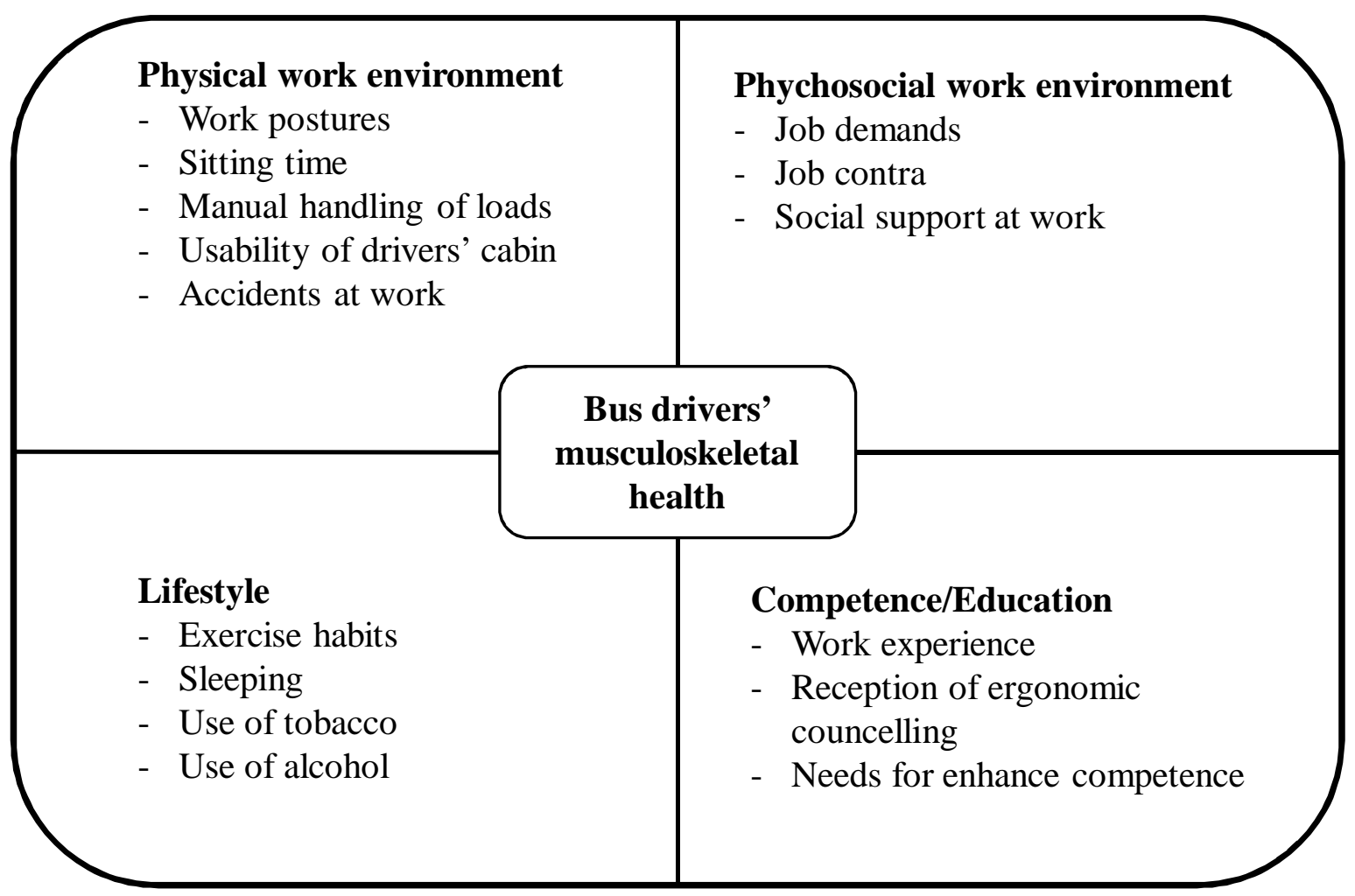

Fig. (2). Theoretical framework of this study.

hazards at work were investigated using five dichotomous questions (yes/no) and one open question.

Current work ability compared with their lifetime best ( 0 = completely unable to work, $10=$ best work ability) was elicited by one question. Later, work ability was classified into the following four groups: excellent (10), good (8-9), moderate (6-7), and poor (0-5) [30].

Work environment was evaluated by questions about physical and psychosocial workload, the usability of bus cabs and seats, ergonomic solutions, accidents at work, accident risk level, and incidents of physical violence. Physical workload was elicited using six questions concerning awkward neck postures, working with hands above shoulder level, awkward back postures, duration of continuous sitting, manual handling of loads, and the weight of loads. In addition, we enquired about the use of lifting devices [31]. Ergonomic solutions that decrease workload were investigated using two open questions.
Psychosocial work exposure (e.g. mental stress, social support at work, skills discretion, time pressure, and psychosocial demands at work) was enquired about using eleven questions adapted from a validated questionnaire [32].

The usability features of the driver's cabin were evaluated using visual analogue scales (VAS) [33, 34], which are 100 $\mathrm{mm}$ long continuous lines with endpoints anchored by 0 (very poor) and 100 (very good). The participants were asked to mark the point on the line that indicated their assessment of each feature. The VAS score was a measured distance (in millimetres) from the 0 scale point.

Accidents at work and incidents of physical violence (at work or on the way to or from work) during the previous 12 months were elicited using one dichotomous question (yes/no). In addition, the respondents were asked to assess their accident risk (none at all, somewhat or large) in relation to 12 items (e.g. time pressure, violent customers, noise) [35].

Table 1. Characteristics of participants $(n=62)$, median (range).

\begin{tabular}{|c|c|c|c|}
\hline & CB Drivers (n=27)* & LDB Drivers (n=35)* & All (n=62)* \\
\hline \hline Gender: women/men $(\%)$ & $44 / 56$ & $47(34-64)$ & $50 / 70$ \\
\hline Age (years) & $52(35-63)$ & $175(153-195)$ & $174(153-197)$ \\
\hline Height $(\mathrm{cm})$ & $172(157-197)$ & $82(53-120)$ & $82(53-120)$ \\
\hline Weight $(\mathrm{kg})$ & $87(54-120)$ & $26(20-40)$ & $27(20-43)$ \\
\hline BMI $\left(\mathrm{kg} / \mathrm{m}^{2}\right)$ & $28(20-43)$ & $14(0.3-29)$ & $15(0.3-37)$ \\
\hline Work experience $($ professional bus driving/years) & $18(1-37)$ & & \\
\hline
\end{tabular}

*The responses of four drivers were not available for the sub-analyses because the drivers did not respond to the question related to city bus driving or long-distance bus driving. 
Lifestyle factors were assessed using ten questions. Five questions concerned exercise habits (amount of daily physical activity, cardiovascular and endurance exercise habits, and exercise during the work day), three questions concerned sleeping habits and two questions were on the use of tobacco and alcohol.

The competence and education of drivers was elicited by three questions. One question concerned drivers' work experience and the second was on ergonomic counselling. A third, open question was used to assess the needs for improving competence in daily work.

The responses of the questionnaire were recorded using Digium Enterprise Software, which was used to provide descriptive statistics of the data. The SAS statistical package (Version 9.2) was used for all of the analyses. The differences between the $\mathrm{CB}$ and LDB drivers regarding MSDs, work ability, load factors, safety at work, and lifestyle factors were analysed using the chi-square test and Fisher's exact test, and the differences in the usability of cabins were evaluated using the Wilcoxon signed rank test.

\section{Interviews}

Three experienced LDB drivers (experience of bus driving between 15-23 years) and one CB driver (5 years) were interviewed during natural work situations (e.g. driving and loading/unloading situations) and at the bus depot or the recreation facilities. In addition, two members of the management were interviewed at the bus depot.

During the interviews, bus drivers were asked to give their opinion of their work ergonomics; what functions well at work and what needs developing. Furthermore, the drivers were asked about the amount and nature of ergonomic advice or recommendations that they had at work. Management was asked the same kinds of questions.

In the course of the interviews, the researchers also observed the drivers' work habits (e.g. working postures and movements), work facilities (e.g. the safety and ergonomics of the premises at the bus depot, in the recreation rooms and inside the bus) and work equipment (e.g. availability of loading aids, personal protective equipment and clothes). The researchers wrote down the results of the observation and took photographs during the observation. These data were used at the workshop, in the reports and in later bus driver training. Informed consent was obtained for the pictures beforehand from both the drivers and the bus service company.

\section{Workshop}

One three-hour workshop was held at the bus company. Its aim was to gather more information on the risk factors of drivers' work, produce ergonomic solutions, and find new ideas for improving bus drivers' musculoskeletal health. Altogether nine people, in addition to the researchers, took part in the workshop. Four of these were experienced bus drivers (two of them worked as mentors and two of them as work safety representatives), three represented middle management, and two were from occupational health care. Previous literature and the results of the interviews and observation of the bus drivers' work were used to aid the discussion.
At the workshop, the participants were divided into three subgroups. First, each subgroup listed the problems affecting bus drivers' musculoskeletal health on some notepaper. These papers were pinned to the wall for the other groups to see. Then the whole group discussed these problems and divided them into categories. After this, work in the subgroups continued. This time each subgroup searched for solutions for diminishing work strain in bus drivers' work. Finally, after the whole group discussion, the best ergonomic solutions were proposed for implementation at the workplace.

\section{RESULTS}

\section{Work Content}

Information on the content of bus drivers' work was gathered through interviews and observation. Both CB and LDB drivers' work contained preparatory tasks prior to setting off on a particular route. While driving, the CB drivers constantly stop at bus stops, open and close the bus doors, collect fares from passengers, interact with passengers, and observe the pedestrians and traffic outside the bus and passenger activity inside the bus.

The LDB drivers' work included these same tasks, but the unbroken periods of driving were longer and the amount of other activities less than those of the $\mathrm{CB}$ drivers. Furthermore, LDB drivers handled the freight (loaded and unloaded it) carried by the long distance buses, i.e. different kinds of packages (weight max. $50 \mathrm{~kg}$ ), and the bus passengers' luggage.

\section{Musculoskeletal Health and Work Ability}

In the questionnaire, both $\mathrm{CB}$ and $\mathrm{LDB}$ drivers reported musculoskeletal pain in various body parts during the previous three months. Drivers most often reported neck pain (71\%), low back pain (56\%) and shoulder pain (43\%). The prevalence of all the MSDs, except knee pain, was higher among the $\mathrm{CB}$ drivers than among the LDB drivers (Table 2). The difference between the $\mathrm{CB}$ and LDB drivers was statistically significant $(\mathrm{p}<0.05)$ for shoulder pain. Of the $C B$ drivers, $70 \%$ assessed their work ability as good or excellent, $15 \%$ as moderate, and $15 \%$ as poor. Of the LDB drivers, the corresponding proportions were $79 \%, 15 \%$, and $6 \%$, respectively.

\section{Work Environment Factors}

The physical work environment risk factors that the $\mathrm{CB}$ bus drivers reported in the questionnaire were different to those reported by the LDB drivers. The $\mathrm{CB}$ drivers more often reported awkward neck $(\mathrm{p}<0.01)$ and back postures $(\mathrm{p}<0.01)$ than the LDB drivers, whereas the LDB drivers performed manual lifting tasks more frequently than the $\mathrm{CB}$ drivers $(\mathrm{p}<0.001)$ (Table 3). LDB drivers also manually handled loads of over $25 \mathrm{~kg}$ more often than the CB drivers $(\mathrm{p}<0.001)$ (Table 3). Time spent sitting (hours/during work time) by the CB drivers was longer than that of the LDB drivers $(p>0.05)$. Leisure time sitting periods of the driver groups did not differ (Table $\mathbf{3}$ ). 
Table 2. Proportion (\%) of city bus (CB) and long-distance bus (LDB) drivers who reported musculoskeletal pain during the preceding month.

\begin{tabular}{|c|c|c|c|}
\hline $\begin{array}{c}\text { Musculoskeletal } \\
\text { Pain }\end{array}$ & $\begin{array}{c}\text { CB Drivers } \\
(\mathbf{n}=27)\end{array}$ & $\begin{array}{l}\text { LDB Drivers } \\
\quad(\mathbf{n}=\mathbf{3 5})\end{array}$ & $\underset{(n=62)}{\text { All }}$ \\
\hline Neck $(\%)$ & 74 & 65 & 71 \\
\hline Shoulders * $(\%)$ & 59 & 31 & 43 \\
\hline Low back $(\%)$ & 63 & 54 & 56 \\
\hline Hips (\%) & 33 & 15 & 23 \\
\hline Knees $(\%)$ & 29 & 31 & 30 \\
\hline Ankles (\%) & 30 & 29 & 30 \\
\hline
\end{tabular}

The CB drivers gave lower values for the usability of bus cabs than the LDB drivers. In particular, the usability of the driver's seat (e.g. design and adjustability of the seat, seat lumbar support, and seat elbow support) was more often considered poor by the CB drivers than by the LDB drivers. There were statistically significant differences between the usability of the CB and LDB drivers' bus seats (Fig. 3).

In the open questions and in the workshop, the bus drivers highlighted the fact that the ergonomics of bus cabs in the old and new buses differed considerably. In addition to bus seat problems, drivers also mentioned that the limited space in the bus cab often prevented good work ergonomics; tall bus drivers in particular had problems with their work posture. According to the bus drivers, other areas needing development were the thermal conditions and voice

Table 3. Physical workload of city bus (CB) and long-distance bus (LDB) drivers.

\begin{tabular}{|c|c|c|c|}
\hline & CB Drivers $(n=27)$ & LDB Drivers $(\mathbf{n}=35)$ & All $(n=62)$ \\
\hline Awkward neck postures at least $1 \mathrm{~h} /$ day, $(\%) * *$ & 26 & 0 & 11 \\
\hline Working with one or both hands above shoulder level, $(\%)$ & 4 & 0 & 2 \\
\hline Awkward back postures at least $1 \mathrm{~h} /$ day, $(\%) * *$ & 11 & 0 & 5 \\
\hline Manual material handling without lifting aids several times a day, $(\%) * * *$ & 0 & 29 & 16 \\
\hline Handling of loads over $25 \mathrm{~kg}$; lifting aids not available, (\%) $* * *$ & 4 & 74 & 43 \\
\hline Sitting time at work (hours), median (range) $*$ & $9(7-12)(n=25)$ & $8(5-11)(n=35)$ & $9(5-12)(n=60)$ \\
\hline Sitting time during leisure time (hours), median (range) & $3(1-8)(n=19)$ & $3(1-7)(n=33)$ & $3(1-8)(n=52)$ \\
\hline
\end{tabular}

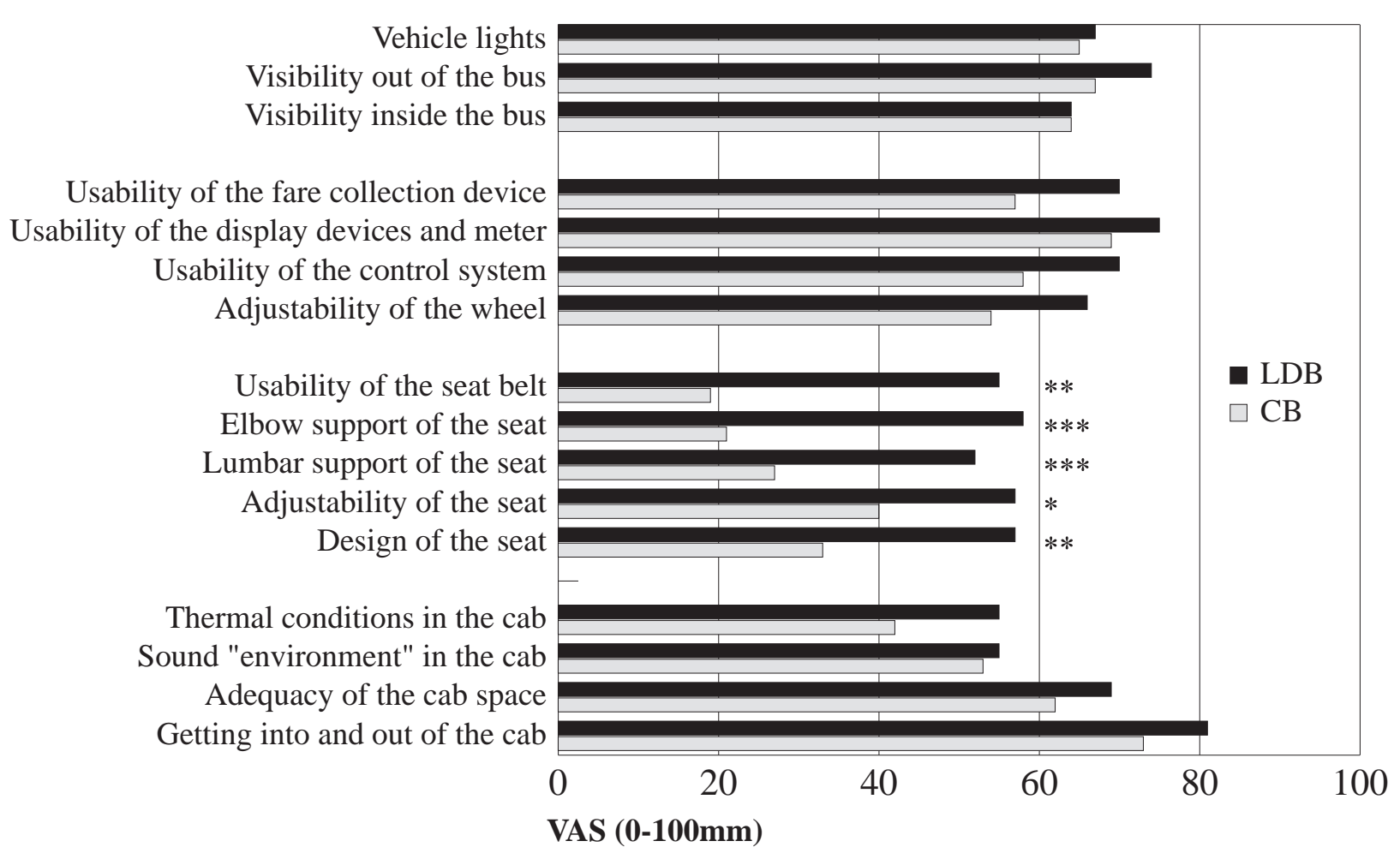

Fig. (3). Perceived usability (VAS, Visual Analogue Scale, $0=$ Very Poor, $100=$ Very Good) of the bus cab. Statistically significant difference between the city bus $(\mathrm{CB}, \mathrm{n}=27)$ and long-distance bus (LDB, $\mathrm{n}=35)$ drivers. $*(\mathrm{p}<0.05) * *(\mathrm{p}<0.01), * * *(\mathrm{p}<0.001)$. 
Table 4. Developmental factors of bus drivers' physical and psychosocial work environment, lifestyle and competence based on results of workshop.

Physical Work Environment
Usability of bus seat
The condition of bus seats should be checked regularly and broken seats should
be fixed faster
- $\quad$ seat surface materials and paddings, seat lumbar and elbow supports,
adjustment handles, seat suspension
Needed $\quad$ more frequent seat cleaning - especially in summer time
- a few extra seats that can be used when a bus seat is being fixed or
- $\quad$ sepaned
personal, changeable bus seat covers for bus drivers

\section{Usability of bus cab}

Needed

- $\quad$ bus engine heaters on all buses (in wintertime)

- functioning air conditioning on all buses - minimizing heat in bus cab in summer time

- $\quad$ proper sun protection for windshields - minimizing glare

- a dark plexiglass between the driver and the passenger seats on both long distance and city buses - better privacy and protection for bus driver

- $\quad$ proper draught excluders on buses - minimizing the draft in the cab

- $\quad$ safe equipment for adjusting bus mirrors or

- better placement for fare collecting bag in bus cab

\section{Load handling}

Better usability of load handling trolleys

Devices for load handling

Reassessment of cargo weight limits

Load handling areas to be kept in better shape

Bus drivers' work clothes

Safe, non-slip working shoes

Gloves for LDB drivers

Warm clothes

\section{Lifestyle}

Bus companies should continue to support bus drivers' physical activities. In addition to this, the bus company should allocate special exercises to drivers who face several health risk factors (e.g. obesity, musculoskeletal disorders etc.).

The bus drivers should enhance their lifestyle by e.g. doing more exercise and getting enough sleep and proper recovery during leisure time.

\section{Psychosocial Work Environment}

\section{Work organization}

More preparation time is needed in the winter or some preparation tasks should be given to cleaning personnel

More time for load handling

Bus drivers' opinions and wishes should be taken into account when designing work shifts

A proper, comfortable rest facilities for CB drivers (a new space was under development at the time)

A sofa is needed in LDB drivers' rest room (because of long waiting periods)

\section{Information flow}

Better information flow about changes concerning work shifts Electrical information board - more efficient, faster information flow A feedback system for reporting deficiencies in the loading/unloading areas

Bus drivers' opinions and ergonomics should be taken into account when buying new buses or repairing old ones

Bus drivers should give the company and/or the loading area personnel feedback on issues that need developing

\section{Work climate and attitudes}

More joint responsibility at work

- concerning e.g. handling cargo - everyone takes their share of the cargo

Everyone is responsible for developing their own competence e.g. learning good lifting and cargo handling ergonomics and using the available cargo handling equipment.

\section{Competence / training}

More training on work ergonomics (especially driving and loading ergonomics and bus seat adjustment), ticketing issues and warm and safe work clothing is needed.

Some of the drivers should be educated as "ergonomic coaches" who could educate co-workers. This could be done in association with the occupational health services (e.g. occupational health physiotherapists). environment of the bus cab, and the location of control devices and the "money bag" (Table 4).

During the previous year, $8 \%$ of the CB drivers and $9 \%$ of the LDB drivers had an accident either at work or on the way to or from work. In both groups, the most often mentioned risk factors for occupational accidents were slipperiness, time pressure, and awkward work postures. Moreover, CB drivers mentioned violent passengers, lack of personal protective equipment and poor work equipment. LDB drivers in turn reported awkward postures and physical workload as the source of occupational accidents. Decreasing time pressure at work, acquiring safer loading equipment and developing safer loading areas were mentioned as developmental targets related to occupational accidents (Table 4).

No statistically significant differences were found between the psychosocial load factors (e.g. time pressure, job control, and mental workload) of the CB drivers and those of the LDB drivers. Psychosocial work environment factors were also highlighted as developmental targets at the workshop. For example, more time for preparation tasks and load handling, better control over work shifts, better information flow at work, and developing bus drivers' own responsibility were mentioned (Table $\mathbf{4}$ ). 
Table 5. Proportion (\%) of city bus (CB) $(n=27)$ and long-distance bus (LDB) $(n=35)$ drivers who reported different lifestyle factors.

\begin{tabular}{|c|c|c|c|}
\hline & CB Drivers $(n=27)$ & LDB Drivers $(\mathbf{n}=\mathbf{3 5})$ & All $(n=62)$ \\
\hline Sleep $\leq 6 \mathrm{~h} /$ night $*(\%)$ & 37 & 11 & 21 \\
\hline Insomnia or awakening 3-5 days/week * $(\%)$ & 35 & 9 & 18 \\
\hline Sleepiness affects work performance (continuously, often, rather often) $* *(\%)$ & 30 & 3 & 14 \\
\hline Physical activity (leisure time exercise $30 \mathrm{~min} /$ day) (\%) & 12 & 20 & 15 \\
\hline Daily smoking $(\%)$ & 37 & 17 & 24 \\
\hline Alcohol consumption (> six units at a time) $(\%)$ & 4 & 3 & 3 \\
\hline
\end{tabular}

Statistically significant difference between CB and LDB drivers $*(\mathrm{p}<0.05), * *(\mathrm{p}<0.01)$.

\section{Lifestyle}

There were no statistically significant differences between the light endurance exercises of the driver groups (Table 5).

The CB drivers slept less $(\mathrm{p}<0.05)$, had more sleep disturbances $(p<0.05)$, suffered sleepiness at work $(p<0.01)$ and smoked (not significant) more often than the LDB drivers (Table 5). Altogether 37\% of the CB drivers and 17\% of the LDB drivers smoked daily (Table 5). There were no statistically significant differences between driver groups' use of alcohol (Table 5).

Discussions on actions needed to enhance and support bus drivers' healthy lifestyle activities revealed that this was considered the responsibility of both the bus company and bus drivers (Table $\mathbf{4}$ ).

\section{Competence and Education}

The drivers were mainly well experienced in their work (Table 1). One third of the bus drivers had received counselling on how to prevent health hazards, especially musculoskeletal disorders in their work. Within this group, $39 \%$ had received instructions for adjusting the steering wheel, $38 \%$ for adjusting the seat and ergonomic sitting position, and $38 \%$ for exercises and other recovery activities they should carry out at work.

According to the bus drivers' answers to the open questions and the discussion in the workshop, the amount of counselling available was insufficient. The bus drivers felt that they needed more training on work ergonomics, ticketing issues, and on company policies concerning systems for work equipment services and sudden changes to work schedules and work tasks (Table 4).

\section{DISCUSSION}

The CB drivers reported MSDs more often than the LDB drivers. The $\mathrm{CB}$ drivers were also more often exposed to psychosocial load factors and unhealthy lifestyle factors than the LDB drivers. Furthermore, the CB drivers' rating of the usability of bus cabs was lower than that of the LDB drivers. Exposure to prolonged sitting was common in both groups, but there were differences in other physical risk factors. The LDB drivers handled loads more often than the CB drivers, whereas $\mathrm{CB}$ drivers reported more awkward working postures. The exposure to so many risk factors emphasizes the importance of both carefully clarifying needs and of using a holistic approach in intervention studies of bus drivers.

To our knowledge, there are no previous studies comparing the lifestyle, work-related risk factors and MSDs of CB and LDB drivers. As in earlier studies, the prevalence of MSDs was high among bus drivers [6]. In our study the most commonly reported pain areas were the neck, low back, and shoulders. In general, the $\mathrm{CB}$ drivers reported more MSDs than LDB drivers. Statistically significant differences were only seen in shoulder pain. This may be due to exposure to awkward neck postures, especially in cities, where drivers have to make quick head movements to see properly. This has been found to be a risk factor for neck and shoulder disorders [36, 37]. Furthermore, the CB drivers' work also included awkward arm and hand postures during the collection of fares. Albert et al. [38] study found that drivers' necks were twisted for approximately a third of their driving time. In our study, one fourth of the CB drivers reported awkward neck postures for at least $1 \mathrm{~h} /$ day. LDB drivers' work in turn contained physical loading and unloading tasks, which created a counterbalance to static driving tasks.

Other explanations for the greater number of MSDs among CB drivers may be differences in driving environments, changing thermal conditions and draft, and bus cab usability. In cities, the roads have more speed bumps and cobble stones and CB driving contains more braking and accelerations than LDB driving [9]. Cold air and draft may worsen MSDs [20]. LDB drivers' rating of the usability of bus cabs was higher than that of the CB drivers. However, both driver groups reported several developmental needs in bus cab ergonomics. Poor design of a bus cab can cause both physical and psychosocial strain to bus drivers [7, 11, 17]. Bus trade companies should be able to concretise these problems and inform manufacturers and designers of them [39].

The risk factors associated with back pain were also present in LDB drivers' work. It is known that prolonged periods of sitting linked to vibration from a bus increase the risk of low back pain among bus drivers [40] (Lis et al. 2007). Studies have also shown that driving, in combination with strenuous work, increases the risk of back disorders [41, 42]. In our study, almost one in three LDB drivers handled loads manually in outdoor circumstances several times a day, 
and lifting aids were often not available. In addition, loading after long periods of static driving time increases the risk of back disorders. In LDB traffic, both men and women handle freight, despite anthropometric differences or differences in muscular force. One third of the bus drivers in this study were women. It is known that women's muscular force is smaller than that of men [43], but the manual loads in bus drivers' work are the same for women.

Prolonged periods of sitting at work is a common risk factor for MSDs among both groups. In this study we analysed the amount of sitting subjectively; this is common in studies concerning sedentary behaviour [12-14]. The CB drivers' sitting time at work varied from 7 to 12 hours and that of LDB drivers from 5 to 11 hours. In van Uffelen et al. [44] study, two thirds of adults spent up to half of their work day sitting. In Finland, $46 \%$ of women and $51 \%$ of men sit for at least six hours per work day [45] but in some occupations, such as that of call centre workers, over $80 \%$ of working time is spent sitting [46]. According to Patel et al. [12], sitting for over six hours per day increases the risk of mortality.

Psychosocial load was somewhat more common among the $\mathrm{CB}$ drivers, who also considered their work to be more time pressured and mentally strenuous than the LDB drivers. As several psychosocial factors at work have been found to associate with the occurrence of MSDs [19], this may be one explanation for $\mathrm{CB}$ drivers having more MSDs. In this study, the bus drivers proposed that work organization, information flow, work climate and workers' own attitudes should be developed in order to enhance their psychosocial health at work.

Overweight, obesity, smoking and sleep disturbances, all of which have shown to be risk factors for low-back pain in particular [47-49], were common among the bus drivers. Every fourth driver in this study was obese, and over $40 \%$ were overweight. The proportion of overweight and obese drivers was greater in the $\mathrm{CB}$ than the LDB drivers' group. Prolonged sitting and an inactive lifestyle can lead to drivers' obesity [7, 12]. The CB drivers smoked more, consumed more alcohol and had more sleep disturbances than the LDB drivers. About one third of the CB drivers suffered sleeping problems and slept under six hours per day. In a Danish study of municipal drivers [2], the proportion of obese drivers was somewhat smaller, but the proportion of smokers was much larger (54\%) than that in our study.

Finally, there may also be a "healthy worker effect" in this industry. A good question is whether some bus drivers start their working career driving long distance buses and change to driving city buses when health problems emerge.

The main strengths of this study were the use of different methods in data collection and the use of a holistic approach to studying bus drivers' work, which was enriched with a participative ergonomics process. This made it possible to obtain in-depth information about the factors affecting the LDB and CB drivers' musculoskeletal problems. It also enabled the bus trade company management, employees, occupational health experts, and researchers to work together in order to find developmental issues that could enhance bus drivers' musculoskeletal health. The developmental issues that needed action in the bus trade company were diverse. Some of them (e.g. repairing the seats) were rather simple and easy to implement, using a minimum amount of money or resources. Other complex developmental needs, such as the need to redesign bus cabs, were out of the bus trade company's hands. However, these still call for attention, in order to make such development needs visible and concrete enough for designers and other relevant stakeholders. Method triangulation (questionnaire, interviews, workshop discussion and observation) was used to confirm the reliability of the study. In addition, validated and previously used questions were used in the questionnaire.

The main limitations of this study were the crosssectional design, the small number of drivers, and the fairly low response rate $(57 \%)$. Therefore, the results should be interpreted with caution. Furthermore, it is not known whether there was selection bias among the participant group, because there was no information about those who did not answer the questionnaire in this study. Indeed the age and gender distribution of the participants complied well with the workers in this bus trade company in general. Care should be taken when generalising the results of this study to apply to all bus drivers in Finland, because in Finland about $90 \%$ of bus drivers are men and $10 \%$ women [50]. In this study, the gender distribution was $2 / 3$ men and $1 / 3$ women. The results of this study can, however, be generalized to cover other small town bus drivers in Finland. In bigger cities, the work-related factors, such as bus route lengths, the amount of customers and other traffic, are somewhat different and thus the results of this study can only be suggestive.

\section{CONCLUSION}

Ergonomic interventions that target bus trade companies must consider the needs of both LDB and CB drivers and apply a holistic approach in order to have an effect on bus drivers' health and work ability. Good co-operation with occupational health service personnel helps bus trade companies achieve their goals.

This study showed that the factors affecting bus drivers' health are the design of the bus cab, the maintenance of buses and work equipment, development of the work organization and work content, company policies, ergonomic counselling, and training on lifestyle and work content issues. It is important to remember that sometimes a minor issue from the company's point of view (e.g. cleaning seats more often) may be of substantial relevance to the bus drivers' work satisfaction.

The results of this study can be utilized in bus trade companies and their occupational health services when developing drivers' work and work environment, and enhancing their health. This information may also be useful in the field of training.

\section{CONFLICT OF INTEREST}

The authors confirm that there is no conflict of interest with the content of this article. 


\section{ACKNOWLEDGEMENTS}

The authors wish to thank the private Finnish bus service company (Oy Pohjolan Liikenne $\mathrm{Ab}$ ) for providing the opportunity for this study. The authors would also like to thank the volunteer bus drivers who made this project possible. Finally, the authors would like to extend their gratitude to Maria Hirvonen, MSc, for her help with the statistical analyses.

\section{REFERENCES}

[1] Poulsen KB. The healthy bus project in Denmark: need for an action potential assessment. Health Promot Int 2004; 19(2): 205-13.

[2] Poulsen KB, Drewes K, Gron S, Petersen PT, Bach E. Reflections on interventions. Experience based on more than 200 interventions initiated in order to improve the health and work environment of 3500 bus drivers. Copenhagen 2005. National Institute of Occupational Health. [Retrieved 2013 January 10] Available from: http://www.arbejdsmiljoforskning.dk/upload/reflections.pdf

[3] Poulsen KB, Jensen SH, Bach E, Schostak JF. Using action research to improve health and the work environment for 3500 municipal bus drivers. Educ Action Res 2007; 15(1): 75-106.

[4] Carayon P. Human factors of complex sociotechnical systems. Appl Ergon 2006; 37(4): 525-35.

[5] Alperovitch ND, Katz LM, Santo Y, Kolman D, Kalichman L. Upper body quadrant pain in bus drivers. Arch Environ Occup Health 2010; 65(4): 218-23.

[6] Alperovitch ND, Santo Y, Masharawi Y, Katz LM, Ushvaev D, Kalichman L. Low back pain among professional bus drivers. Ergonomic and occupational-psychosocial risk factors. Isr Med Assoc J 2010; 12(1): 26-31.

[7] Tse JLM, Flin R, Mearns K. Bus driver well-being review. 50 years of research. Transportation Research Part F. Traffic Psycho Behav 2006; 9(2): 89-114.

[8] Salmon PM, Young KL, Regan MA. Distraction on the buses. A novel framework of ergonomic methods for identifying sources and effects of bus driver distraction. Appl Ergon 2011; 42: 602-10.

[9] Okunribido OO, Shimbles SJ, Magnusson M, Pope M. City bus driving and low back pain: a study of the exposures to posture demands, manual materials handling and whole-body vibration. Appl Ergon 2007; 38(1): 29-38.

[10] Linj A, Tietoa AB. The knowledge of bus services in Finland. [Retrieved from the website of the Finnish Bus and Coach Association (LAL). [Retrieved 2014 May 5]. Available from: http://www.linja-autoliitto.fi/fi/tietoa-alasta/bussijarjestelma/

[11] Gobel M, Springer J, Scherff J. Stress and strain of short haul bus drivers: Psychophysiology as a design oriented method for analysis. Ergonomics 1998; 41(5): 563-80.

[12] Patel AV, Bernstein L, Deka A, et al. Leisure time spent sitting in relation to total mortality in a prospective cohort of US adults. Am J Epidemiol 2010; 172: 419-29.

[13] Finni T, Sääkslahti A, Laukkanen A, Pesola A, Sipilä S. A family based tailored counselling to increase non-exercise physical activity in adults with a sedentary job and physical activity in their young children: design and methods of a year-long randomized controlled trial. BMC Public Health 2011; 11: 944. [Retrieved 2013 March 15] Available from: www.biomedcentral.com/1471-2458/ $11 / 944$

[14] Finni T, Haakana P, Pesola AJ, Pullinen T. Exercise for fitness does not decrease the muscular inactivity time during normal daily life. Scand J Med Sci Sports 2014; 24: 211-9.

[15] Healy GN, Wijndaele K, Dunstan DW, et al. Objectively measured sedentary time, physical activity, and metabolic risk: the Australian Diabetes, Obesity and Lifestyle Study (AusDiab). Diab Care 2008; 31: 369-71.

[16] Matthews CE, Chen KY, Freedson PS, et al. Amount of time spent in sedentary behaviors in the United States, 2003-2004. Am J Epidemiol 2008; 167: 875-81.

[17] Biggs H, Dingsdag D, Stenson N. Fatique factors affecting metropolitan bus drivers: A qualitative investigation. Work 2009; 32: 5-10.

[18] Tamrin SBM, Yokoyama K, Aziz N, Maeda S. Association of risk factors with musculoskeletal disorders among male commercial bus drivers in Malaysia. Hum Factors Ergon Manuf 2014; 24(4): 36985.

[19] Macfarlane GJ, Pallewatte N, Paudyal P, et al. Evaluation of workrelated psychosocial factors and regional musculoskeletal pain: results from a EULAR Task Force. Ann Rheum Dis 2009; 68(6): 885-91.

[20] Van AJ. World at work: truck drivers. Occup Environ Med 2012; 69: 291-5.

[21] Brunoro C, Laerte IS, Bolis I, Abrahao J. Contributions of ergonomics to the construction of bus drivers health and exellence in public transport and at work. Work 2012; 41: 30-5.

[22] Wong CKH, Fung CSC, Siu SH, et al. The impact of work nature, lifestyle, and obesity on health-related quality of life in Chinese professional drivers. J Occup Environ Med 2012; 54(8): 989-94.

[23] Turner LM, Reed DB. Exercise among commercial truck drivers. AAOHJN J 2011; 59(10): 429-36.

[24] French SA, Harnack LJ, Hannan PJ, Mitchell NR, Gerlach AF, Toomey TL. Worksite environment intervention to prevent obesity among metropolitan transit workers. Prev Med 2010; 50(4): 180-5.

[25] Davila EP, Florez H, Fleming LE, et al. Prevalence of the metabolic syndrome among U.S. workers. Diab Care 2010; 33(11): 2390-5.

[26] Dahl S, Kaerlev L, Jensen A, et al. Hospitalization for lifestyle related diseases in long haul drivers compared with other truck drivers and the working population in range. Work 2009; 33(3): 345-53.

[27] Puttonen S, Härmä M, Hublin C. Shift work and cardiovascular disease - pathways from circadian stress to morbidy. Scand J Work Environ Health 2010; 36(2): 96-108.

[28] Cappuccio FP, Cooper D, DÉlia L, Strazzullo P, Miller MA. Sleep duration predicts cardiovascular outcomes: a systematic review and meta-analysis of prospective studies. Eur Heart J 2011; 32(12): 1484-92.

[29] Kuorinka I, Jonsson B, Kilbom A, et al. Standardised Nordic questionnaires for the analysis of musculoskeletal symptoms. Appl Ergon 1987; 18(3): 233-7.

[30] Gould R, Ilmarinen J, Järvisalo J, Koskinen S, Eds. Dimensions of work ability. Results of the Health 2000 -study._Helsinki: Finnish Centre for Pensions, Kela, The National Public Health Institute of Finland, Finn Inst Occup Health 2008.

[31] Perkiö MM, Viluksela M. Työ ja terveys Suomessa. Puhelinhaastattelulomake [Work and Health survey. Telephone interview form][Retrieved 10 February 2015] Available from: www.ttl.fi

[32] Elo AL, Leppänen A, Lindström K, Ropponen T. Occupational stress questionnaire: user's instructions (reveiws 19). Helsinki: Finnish Institute of Occupational Health 1992.

[33] Price DD, McGrath PA, Rafii A, Buckingham B. The validation of visual analogue scales as ratio scale measures for chronic and experimental pain. Pain 1983; 17(1): 45-56.

[34] Beauchamp Y. Application of visual analog scales (VAS) for the comparative evaluation of tool and equipment designs and work methods. Comput Ind Eng 1999; 37(1-2): 289-92.

[35] Perkiö MM, Hirvonen M, Työ SH, Taulukkoraportti [Work and health survey 2012. Statistics]. Helsinki, Finnish Institute of Occupational Health 2013.

[36] Ariens GA, Van MW, Bongers PM, Bouter LM, Van WG. Physical risk factors for neck pain. Scand J Work Environ Health 2000; 26(1): 7-19.

[37] Cote P, Van VG, Cassidy JD, et al. The burden and determinants of neck pain in workers: results of the bone and joint decade 20002010 task force on neck pain and its associated disorders. Spine 2008; 33(4 Suppl): 60-74.

[38] Albert WJ, Everson D, Rae M, Callaghan JP, Croll J, Kuruganti U. Biomechanical and ergonomic assessment of urban transit operators. Work 2014; 47: 33-44.

[39] Reiman A. Holistic work system design and management - a participatory development approach to delivery truck drivers' work outside the cab. PhD [dissertation]. University of Oulu. Department of Industrial Engineering and Management 2013.

[40] Lis AM, Black KM, Korn H, Nordin M. Association between sitting and occupational LPB. Eur Spine J 2007; 16: 283-98.

[41] Kaila KL, Miranda H, Takala EP, et al. The role of past and current strenuous physical work in the association between professional car driving and chronic low-back syndromes: a population-based study. Spine 2011; 36(11): E734-40. 
[42] Okunribido OO, Magnusson M, Pope MH. The role of whole body vibration, posture and manual materials handling as risk factors for low back pain in occupational drivers. Ergonomics 2008; 51(3): 308-29.

[43] Miller AEJ, MacDougall JD, Tamopolsky MA, Sale DG. Gender differences in strength and muscle fiber characteristics. Eur J Appl Phys Occup Phys 1993; 66(3): 254-62.

[44] Van JG, Wong J, Chau JY, et al. Occupational sitting and health risks. Am J Prev Med 2010; 39(4): 379-88.

[45] Sjöström M, Oja P, Hagströmer M, Smith BJ, Bauman A. Healthenhancing physical activity acrossa European Union countries: The Eurobarometer study. J Public Health 2006; 14(5): 291-300.

[46] Toomingas A, Forsman M, Mathiassen SE, Heiden M, Nilsson T. Variation between seated and standing/walking postures among male and female call center operators. BMC Public Health 2012; 12(1): 154 .

[47] Kelly GA, Blake C, Power CK, O'keeffe D, Fullen BM. The association between chronic low back pain and sleep: a systematic review. Clin J Pain 2011; 27(2): 169-81.

[48] Shiri R, Karppinen J, Leino AP, Solovieva S, Viikari JE. The association between obesity and low back pain: a meta-analysis Am J Epidemiol 2010a; 171(2): 135-54.

[49] Shiri R, Karppinen J, Leino AP, Solovieva S, Viikari JE. The association between smoking and low back pain: a meta-analysis. Am J Med 2010b; 123(1): 87 e 7-87 e35.

[50] Statistics Finland. Työlliset ammattiryhmän, sukupuolen, iän ja vuoden mukaan 2010-2011 [Employed persons by occupation group, sex, age, and year 2010-2011]. [Retrieved 25 February 2014] Available from: http://www.stat.fi

(C) Kärmeniemi et al.; Licensee Bentham Open.

This is an open access article licensed under the terms of the Creative Commons Attribution Non-Commercial License (http://creativecommons.org/licenses/by$\mathrm{nc} / 3.0 /$ ) which permits unrestricted, non-commercial use, distribution and reproduction in any medium, provided the work is properly cited. 